Tropical Journal of Pharmaceutical Research February 2019; 18 (2): 429-433

ISSN: $1596-5996$ (print); 1596-9827 (electronic)

(C) Pharmacotherapy Group, Faculty of Pharmacy, University of Benin, Benin City, 300001 Nigeria.

\title{
Effect of two types of anesthesia on postoperative recovery of patients with gastric cancer and changes in the levels of their T lymphocyte subsets
}

\author{
Li Xin', Yang Dan², Chen Yan', Shen Jiang ${ }^{1}$, Hong Tao ${ }^{1 *}$ \\ ${ }^{1}$ Department of Anesthesiology, Changzhou First People's Hospital, ${ }^{2}$ Department of Radiation Oncology, Changzhou Fourth \\ People's Hospital, Changzhou, China
}

*For correspondence: Email: ft1310@163.com

Sent for review: 31 October 2018

Revised accepted: 17 January 2019

\begin{abstract}
Purpose: To investigate the effects of two types of anesthesia on postoperative recovery of patients with gastric cancer (GC), and to assess changes in the levels of their Tlymphocyte subsets.

Methods: Patients with GC (200 cases) were randomly assigned to two groups of 100 patients each: general anesthesia (GA) group and GA + epidural anesthesia (GAEP) group. Fasting venous blood samples $(2 \mathrm{~mL})$ were collected from the patients before anesthesia, and at different time-points: zero time (T0), $1 \mathrm{~h}$ (T1), day 1 (T2), and day 3 (T3) after surgery. CD3+, CD4+, CD8+T, and regulatory $T$ cells (Tregs) were determined using a flow cytometer.

Results: Percent CD3+, CD4+, CD8+T, and ratio of $C D 4+$ to $C D 8+$ in both groups at $1 \mathrm{~h}$ and day 1 after operation were significantly lower than their values before anesthesia $(p<0.05)$. There were significant differences in CD3+ and CD4+ levels between the two groups on day $3(p<0.05)$. Percent peripheral $C D 4+C D 25+T$, and ratio of $C D 4+C D 25+$ to $C D 4+$ in both groups also significantly increased at $1 \mathrm{~h}$ and day 1 after operation, while percent peripheral CD4+, CD25+T and CD4+CD25+ to CD4+ ratio in GAEP group on day 1 after operation were significantly lower than those of GA group $(p<0.05)$. Conclusion: These results suggest that combination of general and epidural anesthesia partly controls the expressions of Tregs, thereby enhancing postoperative recovery of GC patients.
\end{abstract}

Keywords: Gastric cancer, T-lymphocyte subsets, Regulatory T-lymphocytes, Epidural, Anesthesia

\begin{abstract}
This is an Open Access article that uses a funding model which does not charge readers or their institutions for access and distributed under the terms of the Creative Commons Attribution License (http://creativecommons.org/licenses/by/4.0) and the Budapest Open Access Initiative (http://www.budapestopenaccessinitiative.org/read), which permit unrestricted use, distribution, and reproduction in any medium, provided the original work is properly credited.
\end{abstract}

Tropical Journal of Pharmaceutical Research is indexed by Science Citation Index (SciSearch), Scopus, International Pharmaceutical Abstract, Chemical Abstracts, Embase, Index Copernicus, EBSCO, African Index Medicus, JournalSeek, Journal Citation Reports/Science Edition, Directory of Open Access Journals (DOAJ), African Journal Online, Bioline International, Open-J-Gate and Pharmacy Abstracts

\section{INTRODUCTION}

In China, gastric cancer (GC) is ranked first in the incidence of all malignant tumors, and it is the most frequently occurring cancer in the elderly aged 50 years and above [1,2]. Operation-induced trauma, use of different anesthesia and postoperative pain have been shown to have negative impact on postoperative recovery and immunity of patients. Since GC patients have reduced immunity, the inhibition of autoimmune function usually induces complications such as postoperative infection and pyemia which can endanger their lives $[3,4]$.

T-Lymphocyte subsets, especially regulatory $\mathrm{T}$ lymphocytes (Tregs), partly reflect the state of a patient's immunity [5]. Tregs are grouped into 
two: naturally-occurring Tregs and inducible or adaptive Tregs, and their immunosuppressive functions are closely related to autoimmune disorders [6,7]. The aim of the present study was to investigate the effects of two types of anesthesia on postoperative recovery of patients with GC and to assess changes in the levels of their T lymphocyte subsets.

\section{EXPERIMENTAL}

\section{Materials and equipment}

Flow cytometer (CytoFLEX) was purchased from Beckman Coulter, Inc, USA. High speed freezing centrifuge (DL-5M) was obtained from Changsha Xiangyi Centrifuge Co. Ltd., China. Mouse antihuman CD3-FITC, CD4-FITC, CD8-FITC and CD25- PE monoclonal antibodies were products of Abcam Biotechnology Co., UK. This research was approved by the Ethical Committee of Changzhou First People's Hospital (approval no. 20180312), and performed according to the guidelines of Declaration of Helsinki promulgated in 1964 as amended in 1996 [8].

\section{Patients and general information}

A total of 200 patients with GC were recruited over a 2-year period for this study. They were randomly assigned to two groups of 100 patients each: general anesthesia (GA) group and GA + epidural anesthesia (GAEP) group. Patients in GA group consisted of 68 males and 32 females weighing between 46 and $81 \mathrm{~kg}$ (mean weight = $62.74 \pm 5.71 \mathrm{~kg}$ ), and aged 41 to 67 years (mean age $=59.84 \pm 5.67$ years. Group GAEP consisted of 70 males and 30 females weighing between 43 and $78 \mathrm{~kg}$ (mean weight $=61.27 \pm$ $4.57 \mathrm{~kg}$ ), and aged 42 to 66 years (mean age = $54.07 \pm 6.27$ years). Based on the American Society of Anesthesiologists (ASA) grading system, the patients were between grade I and II. There were no significant differences in the clinical data of patients in the two groups. The patients signed written informed consent with their family members.

\section{Inclusion and exclusion criteria}

The inclusion criteria were: (1) patients diagnosed with GC through image examinations such as gastrointestinal radiography, ultrasound and CT scan, pathological and cytological tests, and tumor marker tests; (2) patients who did not undergo chemotherapy, radiotherapy, blood transfusion and medication before commencement of the study; (3) patients who had no infection before surgery; and (4) patients who did not present any obvious liver and kidney dysfunctions.

The exclusion criteria were: (1) patients who suffered from recent infections; (2) patients who had gastrointestinal motility disorder before surgery; (3) patients who had recent vaccination; (4) patients who had other tumors; (5) patients who were carriers of hepatitis B virus, HIV or syphilis; and (6) patients who had mental disorders.

\section{Method of administration of anesthesia}

\section{Group GA}

The patients were injected intramuscularly with $0.1 \mathrm{~g}$ of phenobarbital sodium and $0.5 \mathrm{mg}$ atropine before surgery. Puncture was operated and a catheter inserted into the epidural space between T7 and T8. Thereafter, they received vecuronium bromide $(0.12 \mathrm{mg} / \mathrm{kg})$, fentanyl (2 - 3 $\mu \mathrm{g} / \mathrm{kg})$, and propofol $(2 \mathrm{mg} / \mathrm{kg}$ ) as intravenous induction agents, while mechanical ventilation was carried out via an endotracheal tube. This was immediately followed with the administration of pancuronium bromide to maintain their muscular relaxation, and propofol by continuous intravenous drip (2 - $4 \mathrm{mg} / \mathrm{kg} / \mathrm{h})$. In addition, enroflunine (1 - $2 \%$ ) was given by inhalation to maintain anesthesia, and the end-expiratory concentration was maintained at $0.4-0.9$ MAC. In the radical operation for $\mathrm{GC}$, patients also received additional $3 \mu \mathrm{g} / \mathrm{kg}$ fentanyl and 0.05 $0.08 \mathrm{mg} / \mathrm{kg}$ vecuronium, with $1 \%$ lidocaine administered at $2 \mathrm{~mL} / \mathrm{h}$ post-operation via a selfcontrolled analgesia pump.

\section{Group GAEP}

The patients were injected intramuscularly with $0.1 \mathrm{~g}$ phenobarbital sodium and $0.5 \mathrm{mg}$ atropine before surgery. A puncture was made and a catheter inserted into the epidural space between T7 and T8; $3 \mathrm{~mL}$ of lidocaine (2\%) was injected. After $5 \mathrm{~min}$, an anesthesia plane test was performed on the patients. After determination of the anesthetic effect and endotracheal intubation, an additional $4-6 \mathrm{~mL}$ of $2 \%$ lidocaine was administered through the epidural space, and thereafter maintained at $3-5 \mathrm{ml} / \mathrm{h}$ until the completion of surgery. The block planes were located at T4 to T10.

\section{Study indices and determination of levels of $T$ lymphocyte subsets}

General data for patients such as operation methods, length of incision and operation time were recorded. The time lag before the first 
postoperative flatus or defecation, length of stay in the hospital, diarrhea, throat discomfort, incision infection and pulmonary infection were also recorded. Fasting venous blood samples (2 $\mathrm{mL}$ ) were collected from the patients before anesthesia and at different time points: zero time (T0), $1 \mathrm{~h}$ (T1), day 1 (T2), day 3 (T3) after surgery. The peripheral mononuclear cells were prepared using Ficoll density gradient method. Percent CD3+, CD4+, CD8+T, and Tregs were determined by flow cytometry.

\section{Statistical analysis}

Numeric data are expressed as mean \pm SEM. Statistical analysis was performed using SPSS (version 17.0). Groups were compared using Chi-square $\left(\chi^{2}\right)$ test. Values of $p<0.05$ were considered statistically significant.

\section{RESULTS}

\section{Basic profile of patients}

There were no significant differences in sex, age, operation method, length of incision, and operation time of the patients between the two groups (Table 1).

\section{Outcomes of postoperative recovery condition}

The length of hospital stay in group GAEP was significantly shorter than that of group GA $(p<$ 0.05). The time of the first postoperative flatus or defecation, incidence of diarrhea, throat discomfort and incision infection in group GAEP were not significantly different from those of group GA $(p>0.05)$. There was no incidents of pulmonary infection in the two groups (Table 2).

\section{Changes in levels of lymphocyte subsets of the patients}

Percent CD3+, CD4+, CD8+T, and ratio of CD4+ to CD8+ in both groups at $1 \mathrm{~h}$ and day 1 after operation were significantly lower than their values before anesthesia $(p<0.05)$. However, at day 3 after operation, percent CD3+, CD4+, CD8+T, and CD4+/CD8+ in group $\mathrm{C}$ returned to their levels before anesthesia. There were no significant differences in percent CD3+, CD4+, CD8+T, and CD4+/CD8+ for the two groups at 1 $\mathrm{h}$ and day $1(p<0.05)$. However, there were significant differences in percent CD3+ and CD4+ for the two groups on day $3(p<0.05)$. The results are shown in Table 3.

\section{Levels of Tregs in peripheral blood of the patients}

Percent peripheral CD4+ CD25+T and ratio of CD4+CD25+ to CD4+ in both groups were significantly increased at $1 \mathrm{~h}$ and day 1 after operation. Percent peripheral CD4+ CD25+T and CD4+ CD25+/CD4+ in group GAEP at day 1 after operation were significantly lower than those in group GA $(p<0.05)$. However, at day 3 after operation, percent peripheral CD4+ CD25+T and CD4+ CD25+/CD4+ of both groups nearly returned to the same level prior to anesthesia (Table 4).

Table 1: Basic profile of patients

\begin{tabular}{lcccccccc}
\hline Group & \multicolumn{2}{c}{ Sex } & Age (years) & $\begin{array}{c}\text { Operation } \\
\text { method }\end{array}$ & \multicolumn{2}{c}{ Length of incision (cm) } & $\begin{array}{c}\text { Operation time } \\
\text { (min) }\end{array}$ \\
\cline { 2 - 8 } & Male & Female & & $\begin{array}{c}\text { Proximal } \\
\text { stomach }\end{array}$ & $\begin{array}{c}\text { Distal } \\
\text { stomach }\end{array}$ & $\begin{array}{c}\text { Total } \\
\text { stomach }\end{array}$ & \\
\hline GA & 68 & 32 & $59.84 \pm 5.67$ & 26 & 51 & 23 & $16.85 \pm 3.81$ & $157.12 \pm 36.84$ \\
GAEP & 70 & 30 & $60.74 \pm 5.71$ & 30 & 49 & 21 & $16.72 \pm 3.57$ & $149.22 \pm 38.20$ \\
$\chi^{2}$ & 0.094 & 0.094 & 1.118 & 0.397 & 0.080 & 0.117 & 0.249 & 1.489 \\
$P$ & 0.759 & 0.759 & 0.265 & 0.529 & 0.773 & 0.732 & 0.804 & 0.138 \\
\hline
\end{tabular}

Table 2: Postoperative recovery conditions of patients (mean \pm SD)

\begin{tabular}{lcccccc}
\hline Group & TFPFD (h) & HS (d) & $\begin{array}{c}\text { Diarrhea } \\
(\mathbf{n}, \%)\end{array}$ & TD (n, \%) & II (n, \%) & PI (n, \%) \\
\hline GA $(\mathrm{n}=100)$ & $46.82 \pm 10.24$ & $15 \pm 4$ & $6(6.00)$ & $12(12.00)$ & $2(2.00)$ & $0(0.00)$ \\
GAEP & $44.85 \pm 9.54$ & $10 \pm 3$ & $4(4.00)$ & $8(8.00)$ & $1(1.00)$ & $0(0.00)$ \\
$\chi^{2}$ or T-value & 1.408 & 10.000 & 0.421 & 0.889 & 0.338 & 1.000 \\
$P$-value & 0.161 & 0.000 & 0.516 & 0.346 & 0.561 & 0.000 \\
\hline
\end{tabular}

Key: TFPFD: time of first postoperative flatus or defecation; HS: hospital stay; TD: throat discomfort; II: incision infection; PI: pulmonary infection 
Table 3: Changes in the levels of lymphocyte subsets in patients (n, \%)

\begin{tabular}{llccccc}
\hline Index & Group & $\mathbf{N}$ & T0 & T1 & T2 & T3 \\
\hline CD3 $^{+}$ & GA & 100 & $63.85 \pm 5.81$ & $53.71 \pm 6.81^{\mathrm{a}}$ & $46.22 \pm 8.00^{\mathrm{a}}$ & $50.87 \pm 7.33^{\mathrm{ab}}$ \\
& GAEP & 100 & $64.12 \pm 6.12$ & $52.76 \pm 5.89^{\mathrm{a}}$ & $49.55 \pm 10.28^{\mathrm{a}}$ & $60.25 \pm 10.71$ \\
$\mathrm{CD}^{+}$ & GA & 100 & $38.79 \pm 3.87$ & $29.11 \pm 5.02^{\mathrm{a}}$ & $31.85 \pm 5.99^{\mathrm{a}}$ & $31.28 \pm 8.22^{\mathrm{ab}}$ \\
& GAEP & 100 & $40.12 \pm 4.28$ & $30.17 \pm 3.97^{\mathrm{a}}$ & $33.21 \pm 6.21^{\mathrm{a}}$ & $41.21 \pm 7.19$ \\
$\mathrm{CD}^{+}$ & GA & 100 & $21.36 \pm 2.13$ & $18.27 \pm 2.55^{\mathrm{a}}$ & $18.57 \pm 3.41^{\mathrm{a}}$ & $19.56 \pm 5.41$ \\
& GAEP & 100 & $22.78 \pm 2.41$ & $17.21 \pm 1.98^{\mathrm{a}}$ & $19.27 \pm 3.58^{\mathrm{a}}$ & $22.68 \pm 4.31$ \\
$\mathrm{CD}^{+} / \mathrm{CD}^{+}$ & GAEP & 100 & $1.82 \pm 0.21$ & $1.48 \pm 0.87^{\mathrm{a}}$ & $1.52 \pm 0.33^{\mathrm{a}}$ & $1.54 \pm 0.39^{\mathrm{ab}}$ \\
& GAEP & 100 & $1.82 \pm 0.19$ & $1.42 \pm 0.73^{\mathrm{a}}$ & $1.61 \pm 0.24^{\mathrm{a}}$ & $1.81 \pm 0.47$ \\
\hline${ }^{\mathrm{a} P}<0.05$
\end{tabular}

${ }^{a} P<0.05$ when compared to T0; ${ }^{b} p<0.05$ compared to group $\mathrm{G}$

Table 4: Levels of Tregs in peripheral blood of the patients (n, \%)

\begin{tabular}{lcccccc}
\hline Index & Group & $\mathbf{N}$ & T0 & T1 & T2 & T3 \\
\hline CD4 $^{+}$CD25+ & GA & 100 & $1.58 \pm 0.38$ & $1.83 \pm 0.51^{\mathrm{a}}$ & $2.57 \pm 0.84^{\mathrm{ab}}$ & $1.66 \pm 0.31$ \\
& GAEP & 100 & $1.60 \pm 0.41$ & $1.81 \pm 0.43^{\mathrm{a}}$ & $1.92 \pm 0.62^{\mathrm{a}}$ & $1.61 \pm 0.46$ \\
$\mathrm{CD}^{+} \mathrm{CD}^{+} 5^{+} / \mathrm{CD}^{+}$ & GA & 100 & $0.05 \pm 0.01$ & $0.12 \pm 0.02^{\mathrm{a}}$ & $0.19 \pm 0.08^{\mathrm{ab}}$ & $0.06 \pm 0.02$ \\
& GAEP & 100 & $0.05 \pm 0.01$ & $0.09 \pm 0.02^{\mathrm{a}}$ & $0.12 \pm 0.05^{\mathrm{a}}$ & $0.05 \pm 0.01$ \\
\hline
\end{tabular}

${ }^{a} P<0.05$ when compared to T0; ${ }^{D} p<0.05$ compared to group $\mathrm{G}$

\section{DISCUSSION}

In recent years, the effect of different anesthesia on the treatment of cancers has received huge attention. However, a combination of general and epidural anesthesia not only reduces the dose of anesthesia significantly, but also effectively controls the afferent system of the autonomic nerves from nerve root level, and suppresses changes in the concentration of circulatory adrenocorticotropic hormone (ACTH), and other regulatory molecules. Thus, it may decrease the inhibitory effect of general anesthesia on the immune system [9].

In the present study, there were no significant differences in sex, age, operation method, length of incision, and operation time of the patients between the two groups. The length of stay in the hospital of group GAEP was significantly shorter than that of group GA. The time of the first postoperative flatus or defecation, incidence of diarrhea, throat discomfort and incision infection in group GAEP were not significantly different from those of group GA. There was no incident of pulmonary infection in the two groups. The percentages of $\mathrm{CD} 3+, \mathrm{CD} 4+, \mathrm{CD} 8+\mathrm{T}$, and the ratio of CD4+ to CD8+ in both groups at $1 \mathrm{~h}$ and day 1 after operation were significantly lower than their values before anesthesia. However, at day 3 after operation, the percentages of CD3+, CD4+, CD8+T, and CD4+/CD8+ of group GAEP returned to their levels before anesthesia. There were no significant differences in the percentages of $\mathrm{CD} 3+, \mathrm{CD} 4+, \mathrm{CD} 8+\mathrm{T}$, and $\mathrm{CD} 4+/ \mathrm{CD} 8+$ between the two groups at $1 \mathrm{~h}$ and day 1. However, there were significant differences in the percentages of CD3+ and CD4+ between the two groups at day 3 .
These results suggest that both groups of anesthesia may have little effects on patients' postoperative recovery. Changes in the levels of T lymphocyte subsets play an essential role in the occurrence and development of tumors. Several studies have focused on different $T$ lymphocytes such as CD3+, CD4+, and CD8+. The CD3+ cells are mature lymphocytes in peripheral blood; CD4+ can restrain the growth of tumor cells to a certain degree, while CD8+ exhibits a counter-inhibitory action. Therefore, CD4+/CD8+ is a vital marker that represents total immunity. A decrease in CD4+/CD8+ indicates a compromise of immunologic function and poor prognosis [10-12].

Regulatory T cells (Tregs) refer to CD4+ CD25+, which plays a crucial role in the maintenance of immunologic function, immune response and immune tolerance [13]. Some reports have suggested that Tregs are types of $T$ cell which are negatively regulated. In addition, some authors have speculated that the roles of Tregs in peripheral blood of cancer patients are usually augmented, and that when compared with those with low levels, patients with higher Treg levels have poor prognosis [14,15]. Tregs can restrict the activities of several kinds of $T$ lymphocyte subsets and natural killer (NK) cells, and thus are able to trigger tumor immune tolerance [16].

In this study, percent peripheral $C D 4+C D 25+T$ and ratio of CD4+ CD25+ to CD4+ in both groups were significantly increased at $1 \mathrm{~h}$ and day 1 after operation. Percent peripheral CD4+ CD25+T and CD4+ CD25+/ D4+ in GAEP group at day 1 after operation were significantly lower than those in GA group. However, on day 3 after operation, percent peripheral CD4+ CD25+T and 
CD4+ CD25+ to CD4+ ratio in both groups nearly returned to the same level before anesthesia.

\section{Limitations of the study}

The limitation of this study is the use of a small sample size and a single population.

\section{CONCLUSION}

The results of this study suggest that a combination of general and epidural anesthesia can partly control the expressions of Tregs, thus enhancing postoperative recovery of GA patients.

\section{DECLARATIONS}

\section{Conflict of Interest}

No conflict of interest associated with this work.

\section{Contribution of Authors}

This work was done by the author named in this article and the authors accept all liability resulting from claims which relate to this article and its contents. The study was conceived and designed by Hong Tao; Li Xin, Yang Dan, Chen Ya, Shen Jiang, Hong Tao collected and analysed the data, while Li Xin wrote the text and all authors read and approved the text prior to publication.

\section{REFERENCES}

1. Xia $P, X u X Y$. DKK 3 attenuates the cytotoxic effect of natural killer cells on $C D 133+$ gastric cancer cells. Mol. Carcinog 2017; 56 (7): 1712-1721.

2. Wu H, Liu S, Gong J. VCPA, a novel synthetic derivative of a-tocopheryl succinate, sensitizes human gastric cancer to doxorubicin-induced apoptosis via ROSdependent mitochondrial dysfunction. Cancer Lett 2017; 393: 22-32.

3. Gao $F, W u Z$. Effects of different anesthesia techniques on the balance of Th1/Th2 in patients undergoing radical resection of gastric cancer. Acta Med Univ Sci Technologiae Huazhong 2014; (4): 405-408.
4. Fan CG. Comparative study of postoperative pain levels of gastric cancer in different anesthesia. Prac J Cancer 2014; (11): 1431-1432.

5. Ling $B F$, Hou $Q$, Chen $Y C$. Research progress of regulatory $T$ cell in gastric cancer. Med Recapitulate 2015; 2(3): 426-428.

6. Wang P, Zhang RM. Expression of Treg cells and their relationship with aquaporin 4 in gastric carcinoma. Chin J Modern Med 2013; 23 (34): 20-24.

7. Yang XJ, Su W. Research progress of regulatory $T$ cells in gastric cancer. Cancer Res Clinic 2014; 26(6): 428430.

8. World Health Organization. Declaration of Helsinki. $\mathrm{Br}$ Med J 1996; 313(7070): 1448-1449.

9. Sun $H Z$, Cui $H$, Wang $Z Y$. Effects of different anesthetic techniques on perioperative changes in T-lymphocyte subsets in patients with gastric cancer. Chin $J$ Anesthesiol 2001; 21(4): 220-222.

10. Hou M, Zhou NB, Li H. Morphine and ketamine inhibit immune function of gastric cancer patients by increasing percentage of CD4 (+) CD25 (+) Foxp3 (+) regulatory $T$ cells in vitro. J Surg Res 2016; 203(2): 306-312.

11. Dias-Rodrigues V, Barroso-dePinho N, Abdelhay $E$. Nutrition and immune-modulatory Intervention in Surgical Patients with Gastric Cancer. Nutr Clin Pract 2017; 32(1): 122-129.

12. Chen SL, Cai SR, Zhang XH. Expression of CD4+CD25+ regulatory $T$ cells and Foxp3 in peripheral blood of patients with gastric carcinoma. J Biol Regul Homeost Agents 2016; 30(1): 197-204.

13. Li TT, Wang XH, Ling CZ. Research and progression on anti-lung neoplasm activity and the regulation of $T$ cellular immune; function by polysaccharide from sea cucumber. Chin J Clin 2014; 8(10): 123-125.

14. Liu H, Xu L, Wei JE. Role of CD4+CD25+ regulatory $T$ cells in melatonin-mediated inhibition of murine gastric cancer cell growth in vivo and in vitro. Anat Rec 2011; 294(5): 781-788.

15. Liao J. Effect of chemotherapy on cellular immunity and regulatory $T$ cells of patients with advanced gastric cancer. Med Aesthe Cosmetol 2014; 12(4): 4.

16. Deng B, Ding YB, Wu KY. Elucidation of underlying mechanism and clinical value of increased tumorinfiltrating regulatory $T$ cells in gastric cancer tissue. $J$ Clin Med Prac 2013; 17(21): 36-39. 